Article

\title{
The Effect of Lactobacillus plantarum 299v on Iron Status and Physical Performance in Female Iron-Deficient Athletes: A Randomized Controlled Trial
}

\author{
Ulrika Axling ${ }^{1, *}$, Gunilla Önning ${ }^{1,2}$, Maile A. Combs ${ }^{3}$, Alemtsehay Bogale ${ }^{3}$, \\ Magnus Högström ${ }^{4}$ and Michael Svensson ${ }^{5, *}$ D \\ 1 Probi AB, 22370 Lund, Sweden; gunilla.onning@probi.com \\ 2 Biomedical Nutrition, Pure and Applied Biochemistry, Center for Applied Life Sciences, Lund University, \\ 22100 Lund, Sweden \\ 3 Nutrition and Scientific Affairs Department, The Nature's Bounty Co., Ronkonkoma, NY 11779, USA; \\ mcombs@nbty.com (M.A.C.); abogalewot@nbty.com (A.B.) \\ 4 Sports Medicine Umeå AB and Orthopedics, Department of Surgical and Perioperative Sciences, \\ Umeå University, 90187 Umeå, Sweden; magnus.hogstrom@sportsmedumea.se \\ 5 Section of Sports Medicine, Department of Community Medicine and Rehabilitation, Umeå University, \\ 90187 Umeå, Sweden \\ * Correspondence: ulrika.axling@probi.com (U.A.); michael.svensson@umu.se (M.S.)
}

Received: 7 April 2020; Accepted: 24 April 2020; Published: 30 April 2020

\begin{abstract}
Iron is an essential micronutrient for oxygen transport and mitochondrial metabolism and is critical for physical performance. Compromised iron stores are more commonly found among athletes, and females are especially at risk. Iron deficiency is generally treated using oral iron supplements. However, only a small proportion of ingested iron is absorbed, necessitating higher intakes, which may result in adverse side effects, reduced compliance, and inefficient repletion of iron stores. The probiotic strain Lactobacillus plantarum 299v (Lp299v) significantly increases intestinal iron absorption in meal studies. The present study was conducted to explore the effects of $20 \mathrm{mg}$ of iron with or without Lp299v on iron status, mood state, and physical performance. Fifty-three healthy non-anemic female athletes with low iron stores (ferritin $<30 \mu \mathrm{g} / \mathrm{L}$ ) were randomized, and 39 completed the study. Intake of Lp299v with iron for four weeks increased ferritin levels more than iron alone (13.6 vs. $8.2 \mu \mathrm{g} / \mathrm{L})$, but the difference between the groups was not significant $(p=0.056)$. The mean reticulocyte hemoglobin content increased after intake of Lp299v compared to control (1.5 vs. $0.82 \mathrm{pg}$ ) after 12 weeks, but the difference between the group was not significant $(p=0.083)$. The Profile of Mood States (POMS) questionnaire showed increased vigor with Lp299v vs. iron alone after 12 weeks (3.5 vs. 0.1, $p=0.015$ ). No conclusive effects on physical performance were observed. In conclusion, Lp299v, together with $20 \mathrm{mg}$ of iron, could result in a more substantial and rapid improvement in iron status and improved vigor compared to $20 \mathrm{mg}$ of iron alone. A larger clinical trial is needed to further explore these findings as well as the impact of Lp299v on physical performance.
\end{abstract}

Keywords: Lactobacillus plantarum 299v; DSM 9843; probiotics; athletes; iron-deficiency; physical performance; exercise; ferritin; vigor

\section{Introduction}

Iron deficiency (ID) is a global health problem. Iron deficiency refers to the reduction of iron stores and is the most common cause of anemia [1,2]. Among else, iron is crucial for oxygen transport, mitochondrial energy production, and cellular immune responses [3]. Compromised iron stores, 
even without iron-deficiency anemia, have been shown to negatively affect physical performance and adaptation to training [4-6]. Low iron stores are more commonly found among athletes than in non-athletes, and female athletes are especially at risk [7-14]. The prevalence of ID in females involved in competitive sports has been reported to range from 10 to $38 \%$ [10,11,15-17] and to vary between training seasons $[7,10,18]$.

The increased risk of ID and iron deficiency anemia in athletes is thought to be due to factors, such as foot-strike induced hemolysis, insufficient dietary intake, increased iron losses, and suppressed intestinal iron absorption caused by inflammation [19-22]. Ferritin is the cellular storage protein for iron, and circulating levels are generally considered reflective of total body iron stores [23]. Ferritin seems to adequately identify most of the ID in a majority of athletes [10,11,15-17] and is, therefore, a useful marker of iron status.

Some studies have demonstrated the beneficial effects of iron supplementation on physical performance in women of reproductive age [24], but it has also been questioned whether iron supplementation to iron-deficient non-anemic subjects improves physical performance [5]. Iron deficiency is generally treated using oral iron supplements. More than $50 \%$ of female athletes have been shown to use dietary supplements, and those containing iron appear to be among the most popular [25]. However, a large proportion of the ingested iron typically remains in the gut, necessitating higher intakes, which may result in adverse side effects, reduced compliance, and limited ability to efficiently replete iron stores [26,27]. In addition, heavy training per se can be stressful for the intestinal tract, resulting in gastrointestinal discomfort [28,29]. Furthermore, emerging data suggest that the non-absorbed iron could be harmful through modifications of the gut microbiota, increasing the concentration of intestinal pathogens [30]. Therefore, increasing the absorption of iron could be a strategy for improving iron status and avoid the use of traditional high-dose iron supplements and thereby adverse side effects. It has previously been shown that the probiotic strain Lactobacillus plantarum 299v (Lp299v, LP299V $\left.{ }^{\circledR}\right)$ significantly increases iron absorption in meal studies [31-33]. The use of probiotic supplements for optimizing health, performance, and recovery in athletes has been recently reviewed by the International Society of Sports Nutrition [34].

The aim of this exploratory study was to evaluate the effects of a daily intake of $10^{10}$ colony forming units (CFU) of Lp299v together with $20 \mathrm{mg}$ of iron per day compared to $20 \mathrm{mg}$ of iron alone on iron status, mood status, and parameters relating to physical performance. The study was conducted in a population of healthy, non-anemic, female athletes with low iron stores.

\section{Materials and Methods}

\subsection{Study Design}

The study was a randomized, double-blind, placebo-controlled, parallel study with the objective to evaluate the effect of daily intake over 12 weeks of Lactobacillus plantarum $299 \mathrm{~V}\left(\mathrm{LP} 299 \mathrm{~V}^{\circledR} ; 10^{10} \mathrm{CFU}\right.$ ) and $20 \mathrm{mg}$ of iron (ferrous-fumarate; LpFe) compared to $20 \mathrm{mg}$ of iron alone (CtrlFe) on iron status and physical performance assessed by ergometer cycling tests. The study was comprised of one screening visit and four study visits at baseline, weeks 4,8, and 12. The study was carried out at one study site in Sweden between Aug 2017 and May 2018. All subjects gave their informed consent before participating in the study. Participation was voluntary and could be discontinued at any time without explanation. The study was conducted in accordance with the Declaration of Helsinki, and the protocol was approved by the ethics committee in Umeå, Sweden. The trial was registered at ClinicalTrials.gov prior to the study start (NCT03259997). The subjects were randomized at a ratio of 1:1 to receive Lp299v product or control. The generation of the randomization list was delegated to an independent biostatistician. Stratification was performed based on plasma ferritin levels $(\leq 20 \mu \mathrm{g} / \mathrm{L}$ or $>20 \mu \mathrm{g} / \mathrm{L})$ at baseline in order to reduce the risk of differences in baseline ferritin between the groups. The study subjects were enrolled and assigned to the intervention by the investigator. The allocation of study 
products was not disclosed to the investigator, other staff, or sponsor until clean file was declared. The blinding was maintained throughout the study.

\subsection{Study Population}

In the present study, 365 athletes (231 females and 134 males) were screened in order to find eligible subjects; healthy non-anemic (hemoglobin $\geq 120 \mathrm{~g} / \mathrm{L}$ for females, $\geq 130 \mathrm{~g} / \mathrm{L}$ for males) males and females aged 16-40 years old, with low iron stores (plasma ferritin $<30 \mu \mathrm{g} / \mathrm{L}$ ) and high-sensitive C-reactive protein $(\mathrm{hCRP}) \leq 5 \mathrm{mg} / \mathrm{L}$, engaged in competitive sports and regularly training $\geq 5$ h/week. Exclusion criteria were the use of probiotic products, iron supplementation, or ascorbic acid supplementation during the last 4 weeks prior to the start of the intervention, plans for substantial changes in diet and/or training (as judged by the investigator), and pregnancy or plans for pregnancy within the following 20 weeks. Subjects were instructed not to consume probiotic products, additional iron supplements, or ascorbic acid supplements during the study. Subjects were also asked to avoid changes in the intake of dietary supplements and to avoid major changes in dietary habits. The subjects could not donate or receive blood during the study.

\subsection{Study Product}

The study product was provided as capsules. The Lp299v product (LpFe) contained freeze-dried probiotic Lactobacillus plantarum $299 \mathrm{v}$ at a concentration of $10^{10} \mathrm{CFU} /$ capsule, $20 \mathrm{mg}$ of iron (ferrous-fumarate), maize starch (bulking agent), maltodextrin (bulking agent), cellulose derivatives (coating of iron), and magnesium stearate (processing aid/anti-caking). The capsule consisted of hydroxypropyl methylcellulose and titanium dioxide (white color). The control product (CtrlFe) contained all ingredients except Lp299v. Capsules were of identical appearance. The subjects were instructed to consume the study product, one capsule per day, in connection to the main meal of the day. Compliance was assessed by counting of returned study products and through study diaries.

\subsection{Recruitment and Screening}

Subjects were recruited through local sports clubs and regional sports schools. Hemoglobin $(\mathrm{Hb})$, plasma ferritin, and hCRP were analyzed in order to identify eligible subjects.

\subsection{Demographics and Anthropometrics}

Demographic information (date of birth and gender) was recorded at the screening visit. Height and weight were recorded at the first study visit and were used to calculate body mass index (BMI, $\mathrm{kg} / \mathrm{m}^{2}$ ).

\subsection{Blood Sampling and Analyses}

Blood samples were drawn via a polyethylene catheter inserted into a superficial forearm vein at each study visit. The blood samples were analyzed for hemoglobin, erythrocyte volume fraction (EVF), plasma iron, total iron-binding capacity (TIBC), transferrin saturation, plasma ferritin (P-Ferritin), reticulocytes, mean reticulocyte hemoglobin content (Ret-Hb), hCRP, hepcidin, soluble transferrin receptor (sTfR), and hepcidin at certified university hospital laboratories using standardized and validated procedures. TNF $\alpha$, IL-6, and IL- $1 \beta$ were analyzed using the mesoscale platform according to the manufacturer's instructions.

\subsection{Ergometer Cycling Test}

In order to standardize the ergometer cycling test as much as possible, the subjects were instructed to prepare in the same way $24 \mathrm{~h}$ before each test in terms of food intake and rest. Before the start of the test, adherence to the standardized preparations was confirmed. Subjects were asked to fill out a general health status questionnaire before blood sampling and ergometer cycle test at each of the 
four study visits, and the study personnel ensured that the subjects were in good health to safely carry out the test. Relevant current diseases and medications were recorded.

Subjects performed a standardized ergometer cycling test that was divided into two parts; (1) 30 min of submaximal ergometer cycling starting with 10 min of warm-up at 50 watts (W), followed by $5 \mathrm{~min}$ each at $75 \mathrm{~W}, 100 \mathrm{~W}, 125 \mathrm{~W}$, and $150 \mathrm{~W}$, respectively, then $5 \mathrm{~min}$ of recovery before the start of (2) maximal ergometer cycling until time of exhaustion. The starting workload at the maximal test was individually set depending on the individual's lactate level and the self-rated perceived exertion with the Borg 6-20 RPE scale at the end of the last submaximal workload. The workload increased with 20-25 W each minute until time of exhaustion at the maximal test. The measurement of oxygen uptake $\left(\mathrm{VO}_{2}\right)$ and carbon dioxide production $\left(\mathrm{VCO}_{2}\right)$ was done during the submaximal, as well as the maximal ergometer cycling test through indirect calorimetry (AMIS Sport, Innovision Aps, Glamsbjerg, Denmark). The maximal oxygen uptake $\left(\mathrm{VO}_{2} \mathrm{max}\right)$ was also determined, as the highest mean of 60 consecutive seconds, during the maximal ergometer cycling. Venous blood was drawn via the polyethylene catheter at the end of each submaximal workload, as well as $3 \mathrm{~min}$ after completion of the maximal ergometer cycling test for analyses of lactate using a Biosen $C$ line system (EKF Diagnostics GmbH, Barleben, Germany). Heart rate was measured during submaximal and maximal workloads. A Monark ergometer cycle (Monark Ergomedic 839E, Vansbro, Sweden) and a Polar heart rate monitor with a Polar H7 Sensor (Polar Electro Oy, Kempele, Finland) were used for the test. Self-rated perceived exertion, according to the Borg 6-20 RPE scale [35], was registered at the end of each submaximal workload and maximal workload. Work efficiency, i.e., energy consumption in relation to each workload during ergometer cycling, was calculated from $\mathrm{VO}_{2}$ and $\mathrm{VCO}_{2}$ measured via indirect calorimetry at steady-state during the last minute of each submaximal workload, according to Jeukendrup et al. [36].

\subsection{Profile of Mood States (POMS)}

The Profile of Mood States (POMS) questionnaire, according to McNair et al. [37], was used to assess the Profile of Mood States at each study visit and was carried out prior to the ergometer cycling test. The test includes 65 mood-related adjectives, which are rated on a 5-point Likert scale, ranging from 0 (not at all) to 4 (extremely) in response to the question "How are you feeling right now". Six sub-scores can be derived from the test (vigor, tension, depression, anger, fatigue, and confusion), as well as a total mood score. The results are presented as $\mathrm{T}$ scores.

\subsection{Safety and Gastrointestinal (GI) Well-Being}

Safety was assessed by the recording of adverse events at each study visit, both via discussion with the subject as well as through interpretation of the results from the general health questionnaire and a study diary. Gastrointestinal (GI) wellbeing was evaluated, according to Guyonnet et al. [38]. The subjects were asked to rate their wellbeing/comfort, using a 3-point Likert scale (improved, unchanged, worse) by answering the following question: "How do you consider your GI wellbeing (intestinal transit, stool frequency and consistency, abdominal pain/discomfort, bloating, flatulence/passage of gas, borborygmi/rumbling stomach) in the past 7 days, compared to the period before beginning the consumption of the study product?". The subject rated their GI wellbeing after 4, 8, and 12 weeks of intake of the study product.

\subsection{Statistical Methods}

In this exploratory study, we aimed to include a total of 40 eligible subjects. The Wilcoxon signed-rank test was used when evaluating change over time within each group, and the Wilcoxon rank-sum test was used when evaluating differences between groups. Fisher's exact test was used for evaluation of the prevalence of upper respiratory tract infections (URTI) between the two groups. All reported $p$-values were two-sided and nominal, i.e., not adjusted for multiple testing. Statistical analyses were carried out by an independent biostatistician using Microsoft Excel 2016 (Microsoft Office) and StatXact version 11.1.0 (Cytel Software Corporation, Cambridge, MA, USA). The main analyses 
set consisted of all subjects with no major protocol deviations and compliance above $80 \%$ for each four-week period (per-protocol population). If nothing else was stated, the reported data were from the per-protocol population.

\section{Results}

\subsection{Subject Disposition and Baseline Characteristics}

In total, 365 subjects were screened for eligibility. Fifty-three (53) females fulfilled all inclusion criteria and none of the exclusion criteria and were randomized. During the intervention, 14 subjects were excluded or withdrew their consent. The subject disposition is presented in Figure 1. No eligible male subjects were found in the screening process, and, therefore, only female subjects were included in the study. There were no differences in average training volume, age, body weight, or BMI between the groups at the start of the intervention. The mean age was 22 years, and the mean average training time per week prior to the start of the study was $8 \mathrm{~h}$ per week (Table 1).

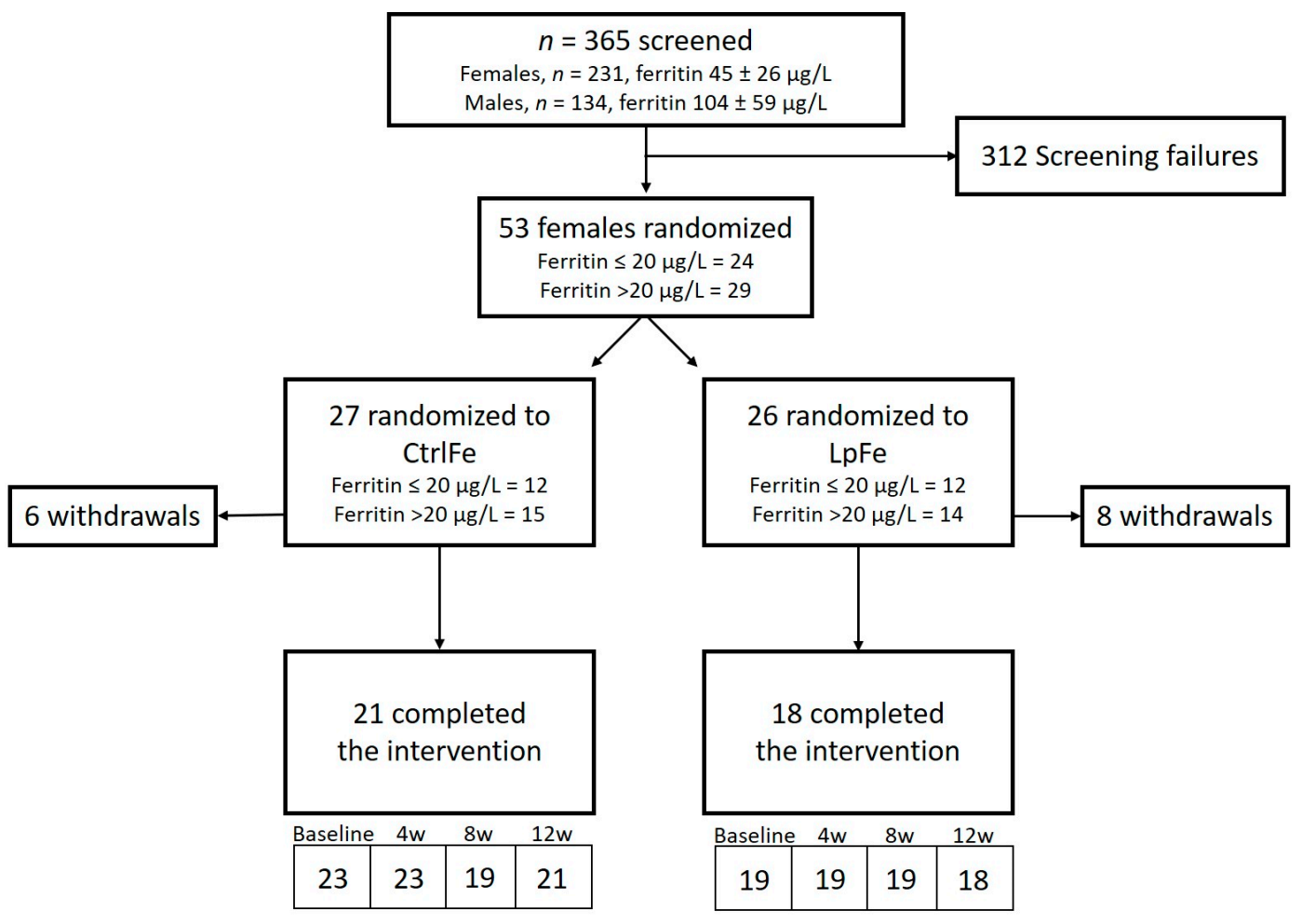

Figure 1. Study flow chart. CtrlFe denotes the group receiving $20 \mathrm{mg}$ of iron alone; LpFe denotes the group receiving $20 \mathrm{mg}$ of iron together with Lactobacillus plantarum $299 \mathrm{v}$. The numbers in the lower boxes correspond to the number of subjects at each study visit.

Table 1. Baseline characteristics.

\begin{tabular}{ccc}
\hline Variables & CtrlFe & LpFe \\
\hline$n$ & 23 & 19 \\
\hline Age (years; SD) & $21.6(6.0)$ & $22.3(3.5)$ \\
Height (cm; SD) & $171(6)$ & $169(5)$ \\
Body weight $(\mathrm{kg} ; \mathrm{SD})$ & $67(7)$ & $66(6)$ \\
BMI $\left(\mathrm{kg} / \mathrm{m}^{2} ; \mathrm{SD}\right)$ & $22.9(1.8)$ & $23.3(2.5)$ \\
Average training hours per week (SD) ${ }^{*}$ & $7.6(2.0)$ & $8.2(2.0)$ \\
$\mathrm{VO}_{2}$ max mL $\times \mathrm{kg}^{-1} \times \mathrm{min}^{-1}$ & $2.8(0.3)$ & $2.9(0.3)$ \\
\hline
\end{tabular}

Data are presented as mean values with standard deviations (SD) for all subjects at the baseline visit. BMI, body mass index. * During the last month prior to the intervention. 


\subsection{Iron Status}

The mean ferritin levels for all the screened subjects were $104 \mu \mathrm{g} / \mathrm{L}$ for males and $45 \mu \mathrm{g} / \mathrm{L}$ for females. Out of the 231 females, 6.5\% had ferritin levels below $15 \mu \mathrm{g} / \mathrm{L}$, and $24 \%$ had ferritin levels between 15 and $29 \mu \mathrm{g} / \mathrm{L}$. The mean plasma ferritin level for the study population was just below $20 \mu \mathrm{g} / \mathrm{L}$ at baseline, indicating low iron stores among the participants at the start of the study, while the mean hemoglobin level was $130 \mathrm{~g} / \mathrm{L}$ (Table 2). Baseline iron status was comparable between the two groups.

Table 2. Parameters related to iron status at baseline.

\begin{tabular}{ccc}
\hline Variables & CtrlFe & LpFe \\
\hline$n$ & $22-23$ & $17-18$ \\
\hline B-Hb $(\mathrm{g} / \mathrm{L})$ & $129.4(9.3)$ & $130.4(8.7)$ \\
P-Ferritin $(\mu \mathrm{g} / \mathrm{L})$ & $19.8(6.8)$ & $19.5(9.3)$ \\
P-Iron $(\mu \mathrm{g} / \mathrm{L})$ & $14.7(6.4)$ & $18.1(7.5)$ \\
P-Transferrin $(\mathrm{g} / \mathrm{L})$ & $3.2(0.5)$ & $3.3(0.5)$ \\
P-Transferrin sat. $(\%)$ & $18.8(7.9)$ & $22.3(10.5)$ \\
B-EVF $(\%)$ & $39(3.0)$ & $39(2.0)$ \\
B-Reticulocytes (pg/L) & $46.6(12.3)$ & $48.5(11.9)$ \\
B-Ret-Hb (pg) & $31.3(2.0)$ & $31.5(2.4)$ \\
sTfR $(\mathrm{mg} / \mathrm{L})$ & $1.3(0.3)$ & $1.5(0.4)$ \\
Hepcidin $(\mathrm{nmol} / \mathrm{L})$ & $1.6(2.1)$ & $1.9(2.0)$ \\
hCRP $(\mathrm{mg} / \mathrm{L})$ & $0.9(0.6)$ & $0.8(0.3)$ \\
\hline
\end{tabular}

Data are presented as mean values with standard deviations (SD) in the per-protocol population. $\mathrm{Hb}$, hemoglobin; EVF, erythrocyte volume fraction; Ret-Hb, reticulocyte hemoglobin content; sTfR, soluble transferrin receptor; hCRP, high-sensitive C-reactive protein.

The ferritin levels increased significantly in both groups, from 19.5 to $43.0 \mu \mathrm{g} / \mathrm{L}$ in the LpFe group $(p<0.001)$ and from 19.8 to $37.8 \mu \mathrm{g} / \mathrm{L}$ in the CtrlFe group $(p<0.001)$ over the whole study period. No significant difference in change from baseline could be detected between the two groups $(13.6 \mu \mathrm{g} / \mathrm{L}$ (95\% CI 8.3-18.8) vs. $8.2 \mu \mathrm{g} / \mathrm{L}$ (4.8-11.6), mean change from baseline to week $4, p=0.056$, Figure 2). There were no differences in the prevalence of ID (ferritin $<20 \mu \mathrm{g} / \mathrm{L}$ ) between the two groups over the study period (10\% in the LpFe and $9 \%$ in the CtrlFe at week 4$)$. After four weeks, 7 out of $17(41 \%)$ in the LpFe group and 7 out of $22(32 \%)$ in the CtrlFe group reached a ferritin level of $30 \mu \mathrm{g} / \mathrm{L}$ or above, and $29 \%$ in the LpFe group and $9 \%$ in the CtrlFe reached a ferritin level of $40 \mu \mathrm{g} / \mathrm{L}$ or above.

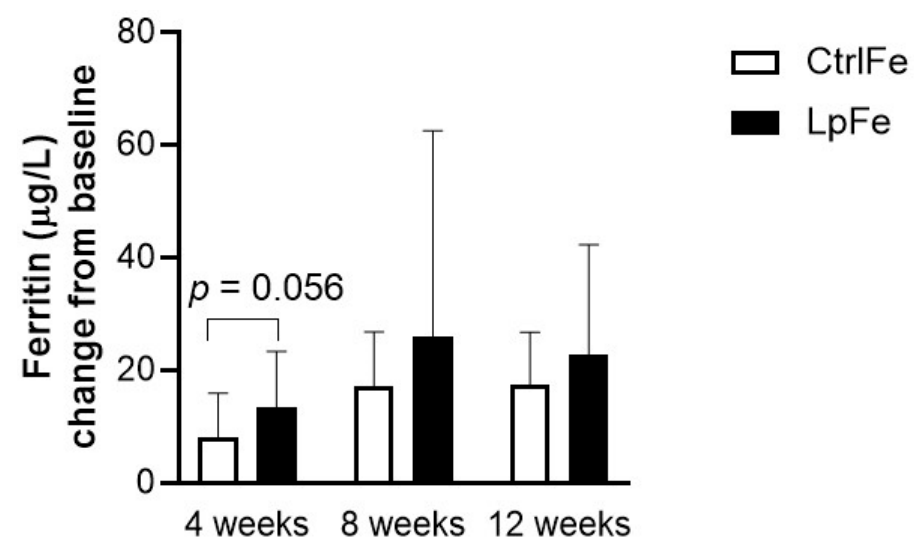

Figure 2. Change from baseline in plasma ferritin at 4,8 , and 12 weeks of intervention. Data are presented as mean values with SD. $n=16$ for LpFe and 22 for CtrlFe at week $4, n=16$ for LpFe and 17 for CtrlFe at week 8, and $n=15$ for LpFe and 17 for CtrlFe at week 12.

When evaluating subgroups based on their baseline plasma ferritin levels (below or above $20 \mu \mathrm{g} / \mathrm{L}$ ), the LpFe subgroup with a ferritin level above $20 \mu \mathrm{g} / \mathrm{L}$ showed a significantly higher increase $(15.4 \mu \mathrm{g} / \mathrm{L}$ 
(95\% CI 6.3-24.6) vs. 6.1 (2.1-10.0) $\mu \mathrm{g} / \mathrm{L}, p=0.0361$, Figure 3) in ferritin after 4 weeks of intake compared to CtrlFe, while the increase in ferritin in the two subgroups with a ferritin level below $20 \mu \mathrm{g} / \mathrm{L} \mathrm{did} \mathrm{not}$ differ (12.9 $\mu \mathrm{g} / \mathrm{L}(95 \%$ CI 6.1-19.6) vs. 11.1 (5.0-17.3) $\mu \mathrm{g} / \mathrm{L}, p=0.5437)$ from each other. No differences were detected for the other time points.
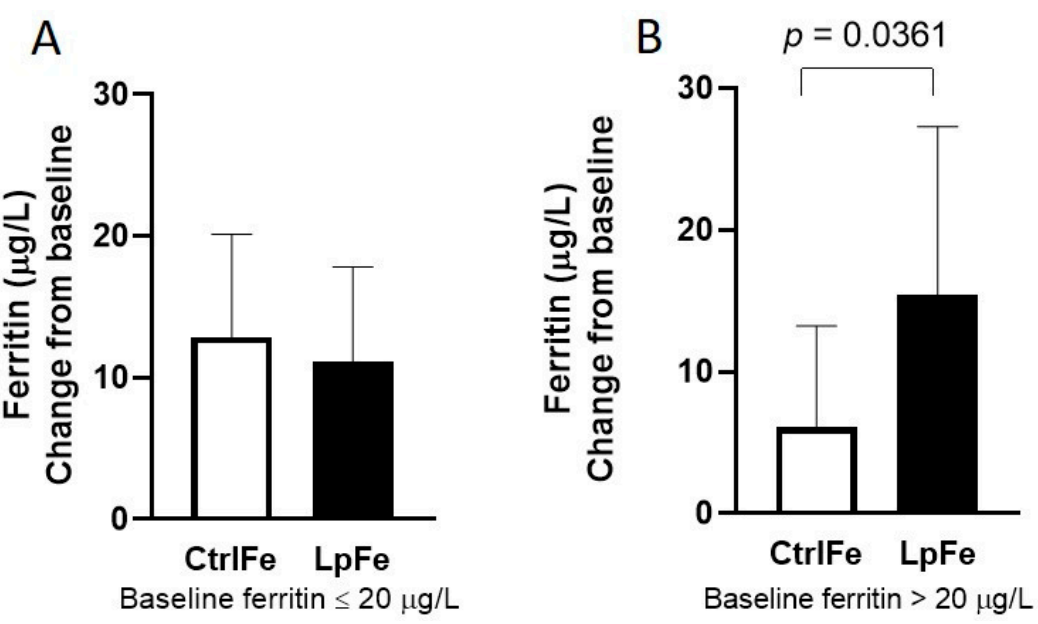

Figure 3. Change from baseline in plasma ferritin after 4 weeks of intervention in the subgroup of subjects with a ferritin level below (A) and above $20 \mu \mathrm{g} / \mathrm{L}$ at baseline (B). Data are presented as mean values with SD. $n=7$ for CtrlFe and 7 for $\mathrm{LpFe}$ in $\mathrm{A}$, and $n=15$ for CtrlFe and 9 for LpFe in B.

The hemoglobin content of the reticulocytes tended to increase in the LpFe group (1.5 pg/L (95\% CI 0.8-2.2) vs. $0.82(0.3-1.3) \mathrm{pg} / \mathrm{L}$, change from baseline to week $12, p=0.0834)$ compared to CtrlFe. The CtrlFe displayed an increase in total plasma iron over the first four weeks compared to the LpFe group (5.6 vs. $-1.6, p=0.0411$, Table 3), but no difference was detected over the whole study ( 2.6 vs. $-0.27, p=0.4373$ for change from baseline to 12 weeks). There were no significant changes over time or between groups in hemoglobin, plasma transferrin, plasma transferrin saturation, EVF, blood reticulocytes, sTfR, hepcidin, and hCRP levels (Table 3).

\subsection{Inflammatory Parameters}

The concentrations of circulating CRP, IL-6, IL- $1 \beta$, and TNF $\alpha$ were low, and there were no detectable differences between the two groups at any of the study visits.

\subsection{Physical Performance}

Based on the results for heart rate, $\mathrm{VO}_{2}, \mathrm{VCO}_{2}$, and ventilation during submaximal ergometer cycling, no evident difference in cardiovascular-respiratory response or work efficiency was found between the baseline and after 4, 8, and 12 weeks of supplementation, respectively, or between groups. Besides, no change in perceived exertion was detected over the intervention period in any group during submaximal ergometer cycling. The blood lactate levels during the submaximal ergometer cycling test displayed incongruent results without any clear change within or between the groups, from baseline and after 4,8 , and 12 weeks of intake, respectively. Despite significantly higher $\mathrm{VO}_{2}$ max following 4 (3.1 vs. 2.9, $p=0.0472$ ), 8 (3.1 vs. 2.8, $p=0.0019$ ), and 12 (3.0 vs. 2.7, $p=0.0447$ ) weeks with the intake of $\mathrm{LpFe}$, compared to intake of CtrlFe (Table 4), no significant change in $\mathrm{VO}_{2}$ max or endurance (time to exhaustion) was detected between the two groups. The LpFe group displayed higher blood lactate levels three minutes post maximal ergometer cycling after 4 (10.8 vs. $8.3, p=0.0139)$ and 8 (10.8 vs. $8.3, p=0.0343)$ weeks of supplementation compared to CtrlFe, together with a tendency towards a higher increase in blood lactate levels compared to CtrlFe after the first four weeks ( 0.47 vs. $-0.72, p=0.0562)$, but no detectable difference was observed over the whole 12 weeks $(0.02$ vs. $-1.05, p=0.3346$,). It should be noted that large differences between subjects were found 
in physical performance and that fewer subjects in both groups performed the cycling test at 8 and 12 weeks than at baseline and 4 weeks due to colds/URTIs), e.g., the change from baseline to week 4 included a larger number of comparisons than the change from baseline to weeks 8 or 12 .

\subsection{Profile of Mood Score}

There was a significant increase in the "vigor" T-score of the POMS questionnaire after 12 weeks in the LpFe group (mean T-score of 58 (95\% CI 55-61) to 61 (CI 58-65), $p=0.044$ ), but no differences were detected in the CtrlFe group (mean T-score of 58 (95\% CI 55-61) to 59 (56-63), $p=0.981$ ). This change from baseline to week 12 was significantly different for the LpFe group compared to the CtrlFe group (3.5 (SD 6.3; 95\% CI 0-7) vs. $0.13(3.5 ;-2-2), p=0.015)$. No other differences between the groups could be detected, neither for the total mood profile nor for any of the other sub-scores.

\subsection{Safety and GI Well-Being}

A total of 51 adverse events were reported -32 by subjects in the CtrlFe group and 19 by subjects in the LpFe group. There were two withdrawals due to adverse events (prolonged URTIs between randomization and the baseline visit), both subjects in the LpFe group. Eighteen subjects in the CtrlFe and 15 subjects in the LpFe group reported at least one adverse event. Upper respiratory tract infections during the study were reported in both the LpFe and CtrlFe groups. The incidence of URTIs in the LpFe group was lower, 5 of 19 (26\%), compared to the CtrlFe group, 14 of $23(61 \% ; p=0.0332)$.

Table 3. Parameters related to iron status. Change from baseline to weeks 4,8 , and 12 .

\begin{tabular}{|c|c|c|c|c|}
\hline Variable & Week & CtrlFe & LpFe & $p$ \\
\hline \multirow{3}{*}{$\mathrm{B}-\mathrm{Hb}(\mathrm{g} / \mathrm{L})$} & Week 4 & $0.55(8.9)$ & $-1.2(9.3)$ & 0.7201 \\
\hline & Week 8 & $2.8(10.7)$ & $-1.06(7.2)$ & 0.1876 \\
\hline & Week 12 & $3.9(8.7)$ & $0.67(7.4)$ & 0.5072 \\
\hline \multirow{3}{*}{ P-Ferritin $(\mu \mathrm{g} / \mathrm{L})$} & Week 4 & $8.2(7.7)$ & 13.6 (9.9) & 0.0565 \\
\hline & Week 8 & $17.3(9.6)$ & $25.9(36.7)$ & 0.9504 \\
\hline & Week 12 & $17.4(9.4)$ & $19.5(19.5)$ & 0.4491 \\
\hline & Week 4 & $5.6(10.1)$ & $-1.6(12.5)$ & 0.0411 \\
\hline \multirow[t]{3}{*}{ P-Iron $(\mu \mathrm{mol} / \mathrm{L})$} & Week 8 & $2.1(8.7)$ & $0.81(11.8)$ & 0.8305 \\
\hline & Week 12 & $2.6(6.7)$ & $-0.27(10.5)$ & 0.4373 \\
\hline & Week 4 & $-0.16(0.31)$ & $-0.29(0.33)$ & 0.3313 \\
\hline \multirow[t]{3}{*}{ P-Transferrin (g/L) } & Week 8 & $-0.31(0.44)$ & $-0.39(0.33)$ & 0.8443 \\
\hline & Week 12 & $-0.18(0.34)$ & $-0.36(0.32)$ & 0.1644 \\
\hline & Week 4 & $8.2(12.5)$ & $-1.6(15.23)$ & 0.0655 \\
\hline \multirow[t]{3}{*}{ P-Transferrin sat. (\%) } & Week 8 & $4.6(10.9)$ & $3.56(15.45)$ & 0.9778 \\
\hline & Week 12 & $5.1(10.3)$ & $2.53(14.67)$ & 0.4056 \\
\hline & Week 4 & $0(0.03)$ & $0(0.03)$ & 0.8531 \\
\hline \multirow{3}{*}{ B-EVF (\%) } & Week 8 & $-0.01(0.02)$ & $-0.01(0.02)$ & 0.3274 \\
\hline & Week 12 & $-0.01(0.02)$ & $-0.01(0.02)$ & 0.4128 \\
\hline & Week 4 & $1.4(9.2)$ & $0.4(14.0)$ & 0.5148 \\
\hline \multirow{3}{*}{ B-Reticulocytes (pg/L) } & Week 8 & $1.1(10.9)$ & $-1.3(11.2)$ & 0.6245 \\
\hline & Week 12 & $3.5(9.7)$ & $3.9(9.3)$ & 0.8014 \\
\hline & Week 4 & $1.1(1.8)$ & $1.0(1.6)$ & 0.9354 \\
\hline \multirow{3}{*}{ B-Ret-Hb (pg) } & Week 8 & $0.8(1.3)$ & $1.3(0.5)$ & 0.2749 \\
\hline & Week 12 & $0.8(0.9)$ & $1.3(0.8)$ & 0.0834 \\
\hline & Week 4 & $-0.14(0.20)$ & $-0.12(0.18)$ & 0.7314 \\
\hline \multirow[t]{3}{*}{$\operatorname{sTfR}(\mathrm{mg} / \mathrm{L})$} & Week 8 & $-0.24(0.27)$ & $-0.15(0.21)$ & 0.3327 \\
\hline & Week 12 & $-0.19(0.15)$ & $-0.18(0.36)$ & 0.3112 \\
\hline & Week 4 & $2.7(7.3)$ & $0.8(3.1)$ & 0.3615 \\
\hline \multirow{2}{*}{ Hepcidin (nmol/L) } & Week 8 & $1.1(3.6)$ & $5.9(8.7)$ & 0.1597 \\
\hline & Week 12 & $2.5(4.1)$ & $3.9(6.8)$ & 0.8076 \\
\hline \multirow{3}{*}{ hCRP (mg/L) } & Week 4 & $-0.05(0.5)$ & $0.07(0.4)$ & 0.7876 \\
\hline & Week 8 & $-0.15(0.5)$ & $0.01(0.3)$ & 0.8789 \\
\hline & Week 12 & $-0.02(0.6)$ & $0.05(0.5)$ & 0.9915 \\
\hline
\end{tabular}

Week 4 = change from baseline over the first 4 weeks, Week $8=$ change from baseline over the first 8 weeks, Week $12=$ change from baseline over the 12-week study; $n$ (CtrlFe): $\Delta \mathrm{V} 3-\mathrm{V} 2=22-23 ; \Delta \mathrm{V} 4-\mathrm{V} 2=16-17$; $\Delta \mathrm{V} 5-\mathrm{V} 2=16-17 ; n$ (LpFe): $\Delta \mathrm{V} 3-\mathrm{V} 2=15-16 ; \Delta \mathrm{V} 4-\mathrm{V} 2=15-16 ; \Delta \mathrm{V} 5-\mathrm{V} 2=15$. 
Table 4. Physical performance parameters during maximal workload. Change from baseline to weeks 4,8 , and 12 .

\begin{tabular}{ccccc}
\hline Parameter & Change & CtrlFe & LpFe & $p$ \\
\hline \multirow{2}{*}{ Endurance (time to exhaustion, min) } & $\Delta \mathrm{V} 3-\mathrm{V} 2$ & $0.29(0.54)$ & $0.35(0.35)$ & 0.8888 \\
\cline { 2 - 5 } & $\Delta \mathrm{V} 4-\mathrm{V} 2$ & $-0.17(1.28)$ & $0.52(0.78)$ & 0.2428 \\
\cline { 2 - 5 } & $\Delta \mathrm{V} 5-\mathrm{V} 2$ & $-0.30(1.74)$ & $0.20(0.69)$ & 0.8467 \\
\hline \multirow{2}{*}{ Heart rate (beats/min) } & $\Delta \mathrm{V} 3-\mathrm{V} 2$ & $0.45(4.56)$ & $0.40(4.10)$ & 0.9935 \\
\cline { 2 - 5 } & $\Delta \mathrm{V} 4-\mathrm{V} 2$ & $-3.22(6.50)$ & $-2.00(2.87)$ & 0.7634 \\
\cline { 2 - 5 } & $\Delta \mathrm{V} 5-\mathrm{V} 2$ & $-2.33(5.12)$ & $1.29(4.51)$ & 0.1243 \\
\hline \multirow{2}{*}{ Lactate $(\mathrm{mmol} / \mathrm{L})$} & $\Delta \mathrm{V} 3-\mathrm{V} 2$ & $0.07(0.14)$ & $0.08(0.13)$ & 0.7357 \\
\cline { 2 - 5 } & $\Delta \mathrm{V} 4-\mathrm{V} 2$ & $-0.08(0.32)$ & $0.09(0.18)$ & 0.2863 \\
\hline & $\Delta \mathrm{V} 5-\mathrm{V} 2$ & $-0.03(0.26)$ & $0.02(0.14)$ & 0.7717 \\
\hline & $\Delta \mathrm{V} 3-\mathrm{V} 2$ & $-0.72(2.05)$ & $0.47(1.84)$ & 0.0562 \\
\hline & $\Delta \mathrm{V} 4-\mathrm{V} 2$ & $-1.22(2.50)$ & $-0.01(1.42)$ & 0.2743 \\
\hline
\end{tabular}

$n$ (CtrlFe: $\Delta \mathrm{V} 3-\mathrm{V} 2=19-20 ; \Delta \mathrm{V} 4-\mathrm{V} 2=8-9 ; \Delta \mathrm{V} 5-\mathrm{V} 2=14-15 ; n$ (LpFe): $\Delta \mathrm{V} 3-\mathrm{V} 2=14-15 ; \Delta \mathrm{V} 4-\mathrm{V} 2=10 ; \Delta \mathrm{V} 5-\mathrm{V} 2=14$.

\section{Discussion}

In the present study, the effect of the probiotic strain Lactobacillus plantarum $299 \mathrm{v}{ }^{\circledR}(\mathrm{Lp} 299 \mathrm{v}$, LP299V ${ }^{\circledR}$ ) on iron status, physical performance, and mood was evaluated in non-anemic female athletes with low iron stores receiving a daily supplement of $20 \mathrm{mg}$ of iron for 12 weeks.

Over the 12-week study, both groups increased their iron status, displayed by a $70 \%$ increase in plasma ferritin after intake of Lp299v with $20 \mathrm{mg}$ of iron as compared to $42 \%$ after $20 \mathrm{mg}$ iron alone, but the difference between groups did not reach statistical significance. However, the LpFe group displayed a tendency towards higher ferritin levels after the first 4 weeks compared to control. This finding is interesting since it is important for iron-deficient athletes to quickly restore iron status without adverse events, which often occur with higher doses of supplemental iron [26]. The LpFe subgroups with ferritin levels above $20 \mu \mathrm{g} / \mathrm{L}$ at baseline showed a significantly higher increase in ferritin after 4 weeks of intake compared to control, while the subgroups with ferritin levels below $20 \mu \mathrm{g} / \mathrm{L} \mathrm{did} \mathrm{not} \mathrm{differ} \mathrm{from} \mathrm{each} \mathrm{other.} \mathrm{Thus,} \mathrm{it} \mathrm{appears} \mathrm{that} \mathrm{the} \mathrm{overall} \mathrm{increase} \mathrm{in} \mathrm{ferritin} \mathrm{with} \mathrm{LpFe}$ is driven by subjects with better baseline iron status. Greater improvement in iron status with LpFe was further indicated by a trend towards increased mean hemoglobin content in the reticulocytes, after 12 weeks of intake. The reticulocyte hemoglobin content is an indicator of cellular iron availability in response to iron supplementation and an early marker of improved erythropoiesis $[39,40]$.

It has previously been shown that the intake of Lp299v improves intestinal iron absorption in meal studies [31-33]. In addition, the intake of Lp299v has been shown to increase the hemoglobin and hematocrit values in anemic rats [41]. The beneficial effect of Lp299v on iron absorption has also been recently examined in a systematic review and meta-analysis [42]. The underlying mechanisms are not fully known, but Lp299v has been shown to increase the amount of ferric iron in in vitro digested meals and drinks. This, in combination with the ability of Lp299v to increase levels of a ferric reductase (duodenal cytochrome B, DcytB) in human intestinal cells (Caco-2/HT29 MTX cells), may explain the positive effect on iron absorption [43]. In the current study, we showed that the effect of Lp299v on intestinal iron absorption translated into an improved iron status in a non-anemic, iron-deficient population when administered in combination with a low dose of iron. Although iron absorption per se was not analyzed in this study, it was theorized that increased iron absorption is at least one of the underlying mechanisms of the improved iron status.

It has been shown that in inflammatory states, a systemic elevation of pro-inflammatory cytokines, such as IL-6 and TNF $\alpha$, inhibits intestinal absorption of iron through elevation of hepcidin [44]. Cytokines may also suppress iron uptake through a hepcidin-independent pathway [45]. Interestingly, 
exhaustive exercise has been shown to increase IL-6 and hepcidin levels [46], which may be one among several factors that cause iron deficiency in athletes following intense periods of training. It is known that intake of Lp299v suppresses inflammatory parameters [47-49], and, therefore, we posited that this could lead to a change in hepcidin expression and, thus, iron absorption. However, in the present study, we were unable to detect any differences over time between the groups for selected inflammatory cytokines or for hepcidin, partially due to the very low cytokine levels. Interestingly, the increase in ferritin after intake of Lp229v was higher in the subgroup of subjects with greater iron status. It is possible that the athletes with the lowest ferritin status had the highest levels of pro-inflammatory cytokines that stimulated an increase in hepcidin level and, thus, increased the inhibition of iron uptake. However, we did not detect any differences in hepcidin, CRP, or IL-6 between the small subgroups in our study. A larger study would be needed to further explore this and investigate inflammatory markers and hepcidin right after an exercise bout when the degree of inflammation is most likely to be higher.

In this study, total plasma iron increased over the first four weeks in the control group compared to the LpFe group. Plasma iron by itself is not normally considered when examining iron status; instead, total iron is used together with transferrin concentrations (i.e., total iron-binding capacity, TIBC) to calculate transferrin saturation (total iron/TIBC). Further investigations are needed to understand the differences between groups in increased plasma iron at 4 weeks in this setting.

Compromised iron status is detrimental to physical performance, and iron supplementation with the intention to increase performance has been used and studied for many years. A meta-analysis, based on data from 22 studies, has shown that iron supplementation in iron-deficient states improves endurance performance and $\mathrm{VO}_{2}$ max in females in some studies but not in all [24]. In the present study, we did not detect any improvement in $\mathrm{VO}_{2}$ max or time to exhaustion with ergometer cycling in any group over the 12 weeks. Blood lactate measurement during submaximal workload did not result in any conclusive results. Although blood lactate measured three minutes after maximal workload was higher in the Lp299v group compared to control at weeks 4 and 8, there was no detectable difference in change over time between the groups. Increased blood lactate levels after maximal exhaustion could indicate increased anaerobic capacity. This finding was not associated with any improvement in performance, as measured in our study.

The assessment of self-perceived mood states revealed an improved vigor in the LpFe group compared to control. The increase in vigor score over time correlated positively with the change in ferritin after intake of Lp299v. Our findings were consistent with those observed previously by McClung et al., who found improved vigor in female soldiers supplemented with iron during military training [50], suggesting that improved iron status is the underlying cause of the increased vigor. However, the mechanisms behind this association remain to be explored in future larger studies on athletes with iron deficiency.

Lp299v has been shown to improve GI wellbeing in a healthy population [51] and in individuals with irritable bowel syndrome [52-54], and it has been, therefore, theorized that supplementation with Lp299v might reduce GI side effects during intense exercise and/or following consumption of iron supplements. However, in the present study, no changes or differences in GI wellbeing were observed in any group. According to the reported adverse events, intake of Lp299v together with $20 \mathrm{mg}$ of iron appeared safe and well-tolerated. Future studies should measure the GI wellbeing of the subjects before the start of the study, and a more robust assessment tool should be applied in order to detect possible differences.

URTIs were detected in both groups in the present study, with a lower prevalence in the Lp299v group compared to the control group. Intake of Lp299v has previously been shown to increase the expression of the activation marker CD25 on CD8 ${ }^{+}$T-cells [55]. However, this study was not primarily designed to compare the prevalence, duration, or severity of URTIs, and future studies are needed to properly evaluate this interesting finding. Endurance athletes are more susceptible to URTIs, and elite 
athletes have a higher rate of URTIs than recreational athletes [56]. Some studies have shown a reduced incidence of URTIs after intake of probiotics, while others have not [57].

The main limitation of this exploratory study was the relatively small sample size, limiting the power and interpretation of data. The URTIs that affected a substantial number of subjects during the intervention weakened the statistical power further, especially at the 8 and 12-week time points.

This was the first study evaluating the effect of a daily intake of Lp299v with a relatively low dose of iron $(20 \mathrm{mg}$ ) on iron status, physical performance, and mood status in female athletes with low iron stores. Taken together, the results indicated that the intake of Lp299v with $20 \mathrm{mg}$ iron could result in a more substantial and rapid improvement in iron status compared to iron alone. Larger studies are warranted in order to further investigate the effect of Lp299v and iron on iron status as well as the impact on physical performance. Future studies should include elucidation of the mode of action as well as effects on immune functions and mood states.

Author Contributions: Conceptualization, G.Ö., M.A.C., A.B., M.S.; methodology, U.A., G.Ö., M.A.C., A.B., M.S. formal analysis, M.S.; investigation, M.S.; resources, M.H., M.S.; writing—original draft preparation, M.S.; writing-review and editing, U.A., G.Ö., M.A.C., A.B., M.H., M.S. All authors have read and agreed to the published version of the manuscript.

Funding: This research was funded by Probi AB and Nature's Bounty Co.

Acknowledgments: The authors would like to acknowledge Ida Söderholm (nurse), Roger Andersson (nurse), Mikael Therell (engineer), and Jens Offerman (research assistant) for valuable assistance with the studyrelated procedures.

Conflicts of Interest: UA and GÖ are employed by Probi AB that is a research and B2B probiotics company. AB. and MAC are employed by The Nature's Bounty Co., a manufacturer, marketer, and online seller of vitamins, dietary supplements, minerals, herbals, protein bars and powders, and ethical beauty products. MS and MH have declared no conflict of interest.

\section{References}

1. Kassebaum, N.J. The Global Burden of Anemia. Hematol. Clin. North Am. 2016, 30, 247-308. [CrossRef] [PubMed]

2. Stoltzfus, R.J. Iron deficiency: Global prevalence and consequences. Food Nutr. Bull. 2003, 24, S99-S103. [CrossRef] [PubMed]

3. Evstatiev, R.; Gasche, C. Iron sensing and signalling. Gut 2011, 61, 933-952. [CrossRef] [PubMed]

4. Haas, J.D.; Brownlie, T. Iron deficiency and reduced work capacity: A critical review of the research to determine a causal relationship. J. Nutr. 2001, 131, 676S-690S. [CrossRef]

5. Rubeor, A.; Goojha, C.; Manning, J.; White, J. Does Iron Supplementation Improve Performance in Iron-Deficient Nonanemic Athletes? Sports Health 2018, 10, 400-405. [CrossRef]

6. Dellavalle, D.M.; Haas, J.D. Impact of iron depletion without anemia on performance in trained endurance athletes at the beginning of a training season: A study of female collegiate rowers. Int. J. Sport Nutr. Exerc. Metab. 2011, 21, 501-506. [CrossRef]

7. Dubnov, G.; Constantini, N.W. Prevalence of iron depletion and anemia in top-level basketball players. Int. J. Sport Nutr. Exerc. Metab. 2004, 14, 30-37. [CrossRef]

8. Landahl, G.; Adolfsson, P.; Börjesson, M.; Mannheimer, C.; Rödjer, S. Iron deficiency and anemia: A common problem in female elite soccer players. Int. J. Sport Nutr. Exerc. Metab. 2005, 15, 689-694. [CrossRef]

9. Dubnov-Raz, G.; Foldes, A.J.; Mann, G.; Magazanik, A.; Siderer, M.; Constantini, N. High Prevalence of Iron Deficiency and Anemia in Female Military Recruits. Mil. Med. 2006, 171, 866-869. [CrossRef]

10. Di Santolo, M.; Stel, G.; Banfi, G.; Gonano, F.; Cauci, S. Anemia and iron status in young fertile non-professional female athletes. Eur. J. Appl. Physiol. 2008, 102, 703-709. [CrossRef]

11. Sandström, G.; Börjesson, M.; Rödjer, S. Iron Deficiency in Adolescent Female Athletes-Is Iron Status Affected by Regular Sporting Activity? Clin. J. Sport Med. 2012, 22, 495-500. [CrossRef] [PubMed]

12. Dellavalle, D.M. Iron Supplementation for Female Athletes. Curr. Sports Med. Rep. 2013, 12, $234-239$. [CrossRef]

13. Parks, R.B.; Hetzel, S.J.; Brooks, M.A. Iron Deficiency and Anemia among Collegiate Athletes. Med. Sci. Sports Exerc. 2017, 49, 1711-1715. [CrossRef] [PubMed] 
14. Alaunyte, I.; Stojceska, V.; Plunkett, A. Iron and the female athlete: A review of dietary treatment methods for improving iron status and exercise performance. J. Int. Soc. Sports Nutr. 2015, 12, 38. [CrossRef] [PubMed]

15. Auersperger, I.; Skof, B.; Leskošek, B.; Knap, B.; Jerin, A.; Lainscak, M. Exercise-Induced Changes in Iron Status and Hepcidin Response in Female Runners. PLoS ONE 2013, 8, e58090. [CrossRef] [PubMed]

16. Alaunyte, I.; Stojceska, V.; Plunkett, A.; Derbyshire, E. Dietary iron intervention using a staple food product for improvement of iron status in female runners. J. Int. Soc. Sports Nutr. 2014, 11, 50. [CrossRef]

17. Malczewska-Lenczowska, J.; Orysiak, J.; Szczepańska, B.; Turowski, D.; Burkhard-Jagodzinska, K.; Gajewski, J. Reticulocyte and erythrocyte hypochromia markers in detection of iron deficiency in adolescent female athletes. Boil. Sport 2017, 34, 111-118. [CrossRef]

18. Malczewska, J.; Raczynski, G.; Stupnicki, R. Iron status in female endurance athletes and in non-athletes. Int. J. Sport Nutr. Exerc. Metab. 2000, 10, 260-276. [CrossRef]

19. DeRuisseau, K.C.; Cheuvront, S.N.; Haymes, E.M.; Sharp, R.G. Sweat iron and zinc losses during prolonged exercise. Int. J. Sport Nutr. Exerc. Metab. 2002, 12, 428-437. [CrossRef]

20. Akiboye, R.D.; Sharma, D.M. Haematuria in Sport: A Review. Eur. Urol. Focus 2019, 5, 912-916. [CrossRef]

21. Dellavalle, D.M.; Haas, J.D. Iron Supplementation Improves Energetic Efficiency in Iron-Depleted Female Rowers. Med. Sci. Sports Exerc. 2014, 46, 1204-1215. [CrossRef] [PubMed]

22. De Oliveira, E.P.; Burini, R.C. The impact of physical exercise on the gastrointestinal tract. Curr. Opin. Clin. Nutr. Metab. Care 2009, 12, 533-538. [CrossRef]

23. Beard, J.; Han, O. Systemic iron status. Biochim. et Biophys. Acta (BBA)-Gen. Subj. 2009, 1790, 584-588. [CrossRef] [PubMed]

24. Pasricha, S.R.; Low, M.S.Y.; Thompson, J.F.; Farrell, A.; De-Regil, L.M. Iron Supplementation Benefits Physical Performance in Women of Reproductive Age: A Systematic Review and Meta-Analysis. J. Nutr. 2014, 144, 906-914. [CrossRef] [PubMed]

25. Heffernan, S.; Horner, K.; De Vito, G.; Conway, G.E. The Role of Mineral and Trace Element Supplementation in Exercise and Athletic Performance: A Systematic Review. Nutrients 2019, 11, 696. [CrossRef] [PubMed]

26. Tolkien, Z.; Stecher, L.; Mander, A.P.; Pereira, D.; Powell, J.J. Ferrous Sulfate Supplementation Causes Significant Gastrointestinal Side-Effects in Adults: A Systematic Review and Meta-Analysis. PLoS ONE 2015, 10, e0117383. [CrossRef]

27. Eid, R.; Arab, N.T.; Greenwood, M.T. Iron mediated toxicity and programmed cell death: A review and a re-examination of existing paradigms. Biochim. et Biophys. Acta (BBA)-Bioenerg. 2017, 1864, 399-430. [CrossRef]

28. Waterman, J.J.; Kapur, R. Upper Gastrointestinal Issues in Athletes. Curr. Sports Med. Rep. 2012, 11, 99-104. [CrossRef]

29. De Oliveira, E.P.; Burini, R.C.; Jeukendrup, A. Gastrointestinal complaints during exercise: Prevalence, etiology, and nutritional recommendations. Sports Med. 2014, 44, 79-85. [CrossRef]

30. Kortman, G.A.M.; Boleij, A.; Swinkels, R.W.; Tjalsma, H. Iron Availability Increases the Pathogenic Potential of Salmonella Typhimurium and Other Enteric Pathogens at the Intestinal Epithelial Interface. PLoS ONE 2012, 7, e29968. [CrossRef]

31. Bering, S.; Suchdev, S.; Sjøltov, L.; Berggren, A.; Tetens, I.; Bukhave, K. A lactic acid-fermented oat gruel increases non-haem iron absorption from a phytate-rich meal in healthy women of childbearing age. Br. J. Nutr. 2006, 96, 80-85. [CrossRef] [PubMed]

32. Hoppe, M.; Önning, G.; Hulthen, L. Freeze-dried Lactobacillus plantarum 299v increases iron absorption in young females-Double isotope sequential single-blind studies in menstruating women. PLoS ONE 2017, 12, e0189141. [CrossRef] [PubMed]

33. Hoppe, M.; Önning, G.; Berggren, A.; Hulthén, L. Probiotic strain Lactobacillus plantarum 299v increases iron absorption from an iron-supplemented fruit drink: A double-isotope cross-over single-blind study in women of reproductive age. Br. J. Nutr. 2015, 114, 1195-1202. [CrossRef]

34. Jäger, R.; Mohr, A.E.; Carpenter, K.C.; Kerksick, C.; Purpura, M.; Moussa, A.; Townsend, J.R.; Lamprecht, M.; West, N.P.; Black, K.; et al. International Society of Sports Nutrition Position Stand: Probiotics. J. Int. Soc. Sports Nutr. 2019, 16, 62. [CrossRef] [PubMed]

35. Borg, E.; Kaijser, L. A comparison between three rating scales for perceived exertion and two different work tests. Scand. J. Med. Sci. Sports 2006, 16, 57-69. [CrossRef] [PubMed] 
36. Jeukendrup, A.E.; Wallis, G.A. Measurement of Substrate Oxidation During Exercise by Means of Gas Exchange Measurements. Int. J. Sports Med. 2005, 26, 28-37. [CrossRef] [PubMed]

37. McNair, D.M.; Lorr, M.; Droppleman, L.F. Manual for the Profile of Mood States; Educational and Industrial Testing Services: San Diego, CA, USA, 1971.

38. Guyonnet, D.; Naliboff, B.; Rondeau, P.; Mayer, E.; Chassany, O. Gastrointestinal well-being in subjects reporting mild gastrointestinal discomfort: Characteristics and properties of a global assessment measure. Br. J. Nutr. 2013, 110, 1263-1271. [CrossRef] [PubMed]

39. Gelaw, Y.; Woldu, B.; Melku, M. The Role of Reticulocyte Hemoglobin Content for Diagnosis of Iron Deficiency and Iron Deficiency Anemia, and Monitoring of Iron Therapy: A Literature Review. Clin. Lab. 2019, 65, 65. [CrossRef]

40. Toki, Y.; Ikuta, K.; Kawahara, Y.; Niizeki, N.; Kon, M.; Enomoto, M.; Tada, Y.; Hatayama, M.; Yamamoto, M.; Ito, S.; et al. Reticulocyte hemoglobin equivalent as a potential marker for diagnosis of iron deficiency. Int. J. Hematol. 2017, 106, 116-125. [CrossRef]

41. Adiki, S.K.; Perla, C.K.; Saha, G.; Katakam, P.; Theendra, V. Enhancement in Iron Absorption on Intake of Chemometrically Optimized Ratio of Probiotic Strain Lactobacillus plantarum 299v with Iron Supplement Pearl Millet. Boil. Trace Element Res. 2018, 190, 150-156. [CrossRef]

42. Vonderheid, S.C.; Tussing-Humphreys, L.; Park, C.; Pauls, H.; Hemphill, N.O.; LaBomascus, B.; McLeod, A.; Koenig, M.D. A Systematic Review and Meta-Analysis on the Effects of Probiotic Species on Iron Absorption and Iron Status. Nutrients 2019, 11, 2938. [CrossRef]

43. Sandberg, A.S.; Önning, G.; Engström, N.; Scheers, N. Iron Supplements Containing Lactobacillus plantarum 299v Increase Ferric Iron and Up-regulate the Ferric Reductase DCYTB in Human Caco-2/HT29 MTX Co-Cultures. Nutrients 2018, 10, 1949. [CrossRef] [PubMed]

44. Verma, S.; Cherayil, B.J. Iron and inflammation-The gut reaction. Metallomics 2017, 9, 101-111. [CrossRef] [PubMed]

45. Guida, C.; Altamura, S.; Klein, F.A.; Galy, B.; Boutros, M.; Ulmer, A.J.; Hentze, M.W.; Muckenthaler, M.U. A novel inflammatory pathway mediating rapid hepcidin-independent hypoferremia. Blood 2015, 125, 2265-2275. [CrossRef] [PubMed]

46. Domínguez, R.; Sánchez-Oliver, A.J.; Mata-Ordoñez, F.; Feria-Madueño, A.; Grimaldi-Puyana, M.; López-Samanes, Á.; Pérez-López, A. Effects of an Acute Exercise Bout on Serum Hepcidin Levels. Nutrients 2018, 10, 209. [CrossRef]

47. Malik, M.; Suboc, T.M.; Tyagi, S.; Salzman, N.; Wang, J.; Ying, R.; Tanner, M.J.; Kakarla, M.; Baker, J.E.; Widlansky, M.E. Lactobacillus plantarum 299v Supplementation Improves Vascular Endothelial Function and Reduces Inflammatory Biomarkers in Men With Stable Coronary Artery Disease. Circ. Res. 2018, 123, 1091-1102. [CrossRef]

48. McNaught, C.; Woodcock, N.; Anderson, A.; MacFie, J. A prospective randomised trial of probiotics in critically ill patients. Clin. Nutr. 2005, 24, 211-219. [CrossRef]

49. Naruszewicz, M.; Johansson, M.L.; Zapolska-Downar, D.; Bukowska, H. Effect of Lactobacillus plantarum 299v on cardiovascular disease risk factors in smokers. Am. J. Clin. Nutr. 2002, 76, 1249-1255. [CrossRef]

50. McClung, J.P.; Karl, J.P.; Cable, S.J.; Williams, K.W.; Nindl, B.C.; Young, A.J.; Lieberman, H.R. Randomized, double-blind, placebo-controlled trial of iron supplementation in female soldiers during military training: Effects on iron status, physical performance, and mood. Am. J. Clin. Nutr. 2009, 90, 124-131. [CrossRef]

51. Johansson, M.L.; Nobaek, S.; Berggren, A.; Nyman, M.E.; Björck, I.; Ahrné, S.; Jeppsson, B.; Molin, G. Survival of Lactobacillus plantarum DSM $9843(299 \mathrm{v})$, and effect on the short-chain fatty acid content of faeces after ingestion of a rose-hip drink with fermented oats. Int. J. Food Microbiol. 1998, 42, 29-38. [CrossRef]

52. Nobaek, S.; Johansson, M.L.; Molin, G.; Ahrné, S.; Jeppsson, B. Alteration of intestinal microflora is associated with reduction in abdominal bloating and pain in patients with irritable bowel syndrome. Am. J. Gastroenterol. 2000, 95, 1231-1238. [CrossRef] [PubMed]

53. Niedzielin, K.; Kordecki, H.; Birkenfeld, B. A controlled, double-blind, randomized study on the efficacy of Lactobacillus plantarum 299V in patients with irritable bowel syndrome. Eur. J. Gastroenterol. Hepatol. 2001, 13, 1143-1147. [CrossRef] [PubMed]

54. Ducrotté, P.; Sawant, P.; Jayanthi, V. Clinical trial: Lactobacillus plantarum 299v (DSM 9843) improves symptoms of irritable bowel syndrome. World J. Gastroenterol. 2012, 18, 4012-4018. 
55. Rask, C.; Adlerberth, I.; Berggren, A.; Ahren, I.L.; Wold, A. Differential effect on cell-mediated immunity in human volunteers after intake of different lactobacilli. Clin. Exp. Immunol. 2013, 172, 321-332. [CrossRef] [PubMed]

56. Spence, L.; Brown, W.J.; Pyne, D.; Nissen, M.; Sloots, T.P.; McCormack, J.G.; Locke, A.S.; Fricker, P.A. Incidence, Etiology, and Symptomatology of Upper Respiratory Illness in Elite Athletes. Med. Sci. Sports Exerc. 2007, 39, 577-586. [CrossRef]

57. Colbey, C.; Cox, A.J.; Pyne, D.; Zhang, P.; Cripps, A.W.; West, N.P. Upper Respiratory Symptoms, Gut Health and Mucosal Immunity in Athletes. Sports Med. 2018, 48, 65-77. [CrossRef] [PubMed]

(C) 2020 by the authors. Licensee MDPI, Basel, Switzerland. This article is an open access article distributed under the terms and conditions of the Creative Commons Attribution (CC BY) license (http://creativecommons.org/licenses/by/4.0/). 